\title{
Performance analysis of the Single-Phase Grid-Connected Inverter of a photovoltaic system in water and wind applications
}

\author{
Dariusz Borkowski ${ }^{1, a}$ \\ ${ }^{1}$ Institute of Electromechanical Energy Conversion, Cracow University of Technology, Krakow 31-155, Poland
}

\begin{abstract}
Single-phase grid connected inverters are nowadays broadly developed and tested in various types of applications especially in photovoltaic systems. The main aim of the inverter control strategy is to extract the maximum energy from the PV system which corresponds to the maximum power at certain conditions. However, the MPPT methods are also important in other renewable energy conversion systems. This paper analyses the performance of a commercially available photovoltaic inverter in water and wind systems. Presented models are implemented in a laboratory test bench in the form of torque characteristics realised by an induction motor fed by the inverter with vector control. The parameters are scaled into relative variables to provide a proper performance comparison. Presented tests include step response to assess the performance of a system dynamic. The dynamic tests showed a fast response of the investigated systems. The MPPT tracking accuracy tested under realistic profiles is similar for both cases: $98 \%$ and $96 \%$ respectively for the wind and water systems. These results prove the satisfactory performance of the MPPT of the PV microinverter in these applications.
\end{abstract}

\section{Introduction}

Nowadays photovoltaic (PV) system technologies become decentralized where each PV module has its own inverter. This concept provides the optimal operation of an individual module and supports the easy change of the system topology [1]. The low power single-phase inverter which is connected to the grid is called the ac-module microinverter [2].

The topology of the microinverter is categorized firstly depending on the power processing stages into single- and multiple stages what is defined by the place of the decoupling capacitor. Next grouping is distinguished by the isolation transformer which can work at line frequency (LFT) or high frequency (HFT). In practice the HFT is used due to the low size and costs. From the grid side, the inverter target is to inject the sinusoidal current thus it operates as a current source [3].

The main aim of the inverter control strategy is to extract the maximum energy from the PV system which correspond to the maximum power at certain conditions. Due to the environmental variations the control techniques have to track the maximum power point (MPP) with a high efficiency [4]. In general two types of the MPPT strategies may be defined: indirect and direct control. The indirect strategies use the database with characteristic curves as a function of irradiances and temperatures for the specific PV type. The direct methods base on the various types of seeking methods without any prior knowledge of the PV features [5]. Usually PV microinverters need the simple and cheap MPPT algorithms therefore the most popular are direct techniques ex.: the hill climbing method or the perturb and observe $(\mathrm{P} \& \mathrm{O})$ techniques.

However, the MPPT methods are important also in other renewable energy conversion systems. Wind turbines use these techniques to optimize the turbine speed under the various wind velocities. The indirect methods called the lookup table use the database or pre-known relationship to track the maximum power or maximum torque. Some variants ex. the tip speed ratio method, requires a wind speed sensor to provide the fast control action. The direct methods are similar to the MPPT of PV systems. The most popular is the hill climbing search (HCS) control which may be implemented by perturbing the control parameters and observe the output power (P\&O) [6]. Extended versions engage the artificial neural network (ANN) effective after comprehensive training and/or the fuzzy logic controller which should be designed to the specific system. The wind speed fluctuations may result in inefficiency caused by slow response of the $\mathrm{P} \& \mathrm{O}$ methods. This problem may be solved by using the various control parameters for perturbing [7].

Another renewable energy source which may gain advantages from MPPT techniques is a water turbine. Variable speed techniques which become popular in hydropower solutions [8-10] create opportunity to implement the adaptive methods [11]. The scientific literature is poor and limited mainly to the "run of the river" small hydropower plants (SHP). Here the controller has two main functions: provide the possible highest conversion efficiency and maintain upper water on the constant level, what results in a maximal energy

\footnotetext{
a Corresponding author: dborkowski@pk.edu.pl
} 
production. These tasks may be integrated in the one controller [12] or realized by the two separate governors [13]. However, especially attractive types of small hydropower are the reservoir plants working with the variable speed where the MPPT technique may be easily implemented.

The presented three types of renewable energy sources differ significantly due to the control variables and time constants. In spite of this the similar control techniques may be used. The MPPT direct methods seem to be the most appropriate.

This paper presents the possibility and analysis of the energy conversion effectiveness of the low power wind turbine and the reservoir SHP that use the singlephase grid-connected inverters designed for photovoltaic systems. The wind and water turbines are modelled by the torque characteristics and are implemented in the laboratory test bench of $1 \mathrm{~kW}$ nominal power. The commercially available PV inverter is used.

\section{Wind turbine model}

The mechanical torque produced by a wind turbine may be defined as follows [7].

$$
T_{w}=\frac{1}{2 \omega_{w}} \cdot \rho_{w} \cdot C_{p} \cdot A \cdot v_{w}^{3}
$$

where:

$\omega_{w}$ - turbine angular velocity $(\mathrm{rad} / \mathrm{s})$,

$\rho_{w}$ - air density $\left(\mathrm{kg} / \mathrm{m}^{3}\right)$,

$C_{p}$ - power coefficient (-),

$A$ - wind turbine swept area $\left(\mathrm{m}^{2}\right)$,

$v_{w}$ - wind speed $(\mathrm{m} / \mathrm{s})$.

The power coefficient is a nonlinear function of tip speed ratio $\lambda$ as well as the turbine pitch angle $\beta$ and can be approximated by expression (2) [14].

$$
\begin{gathered}
C_{p}=0.5176 \cdot\left(\frac{116}{\lambda_{\mathrm{i}}}-0.4 \cdot \beta-5\right) \cdot e^{\frac{21}{\lambda_{i}}}+0.0068 \cdot \lambda \\
\lambda_{i}=\left(\frac{1}{\lambda+0.08 \cdot \beta}-\frac{0.035}{\beta^{3}+1}\right), \lambda=\frac{R \cdot \omega_{w}}{v_{w}}
\end{gathered}
$$

where: $R$ - wind turbine radius $(\mathrm{m})$.

To simplify the analysis let assume that the pitch angle is constant and equals 0 . The power coefficient curve is presented in Fig. 1a. Taking the reference values: $C_{p \max }-$ maximal $C_{p}$ coefficient, $\lambda_{\text {opt }}$ - optimal tip speed ratio as relative variables, the power coefficient curve is scaled as presented in Fig. 1b

The relative torque of the wind turbine can be calculated from formula (3) and it is shown in Fig. 2a at different wind speeds.

$$
T_{w}^{r}=\frac{1}{\omega_{w}^{r}} \cdot C_{p}^{r} \cdot v_{w}^{r 3}
$$

where: $C_{p}^{r}=\frac{C_{p}}{C_{p N}}, \omega_{w}^{r}=\frac{\omega_{w}}{\omega_{w N}}, v_{w}^{r}=\frac{v_{w}}{v_{w N}}$.
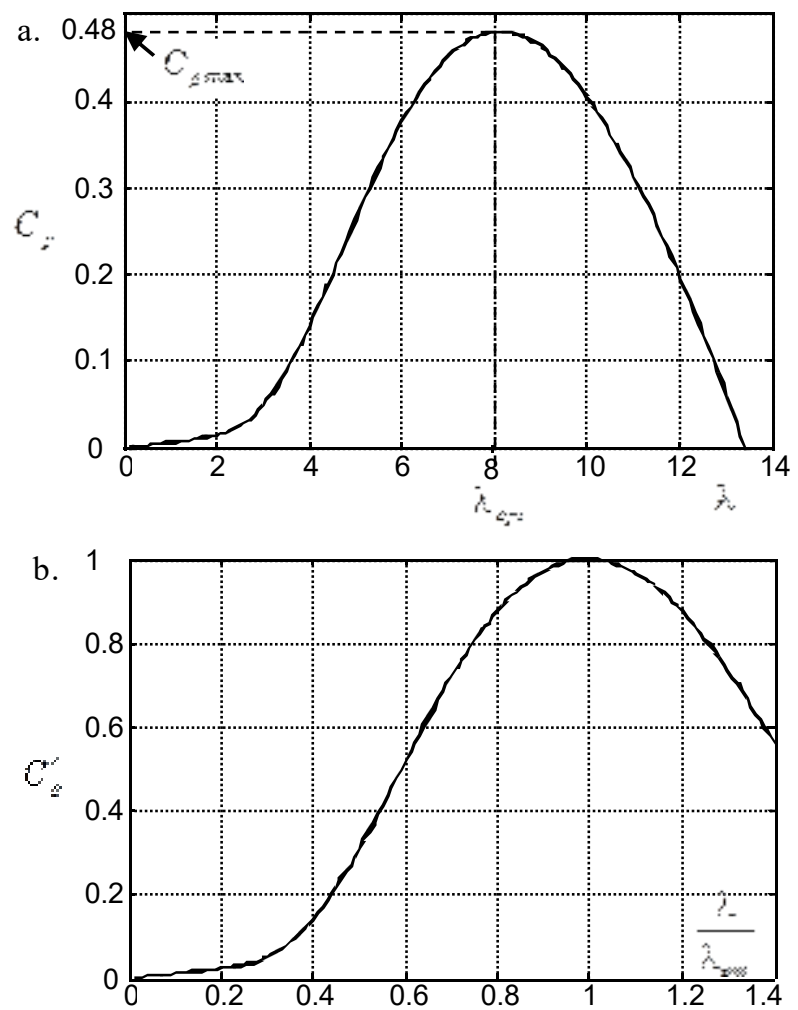

Figure 1. Power coefficient curve: a.) natural units b.) relative variables.
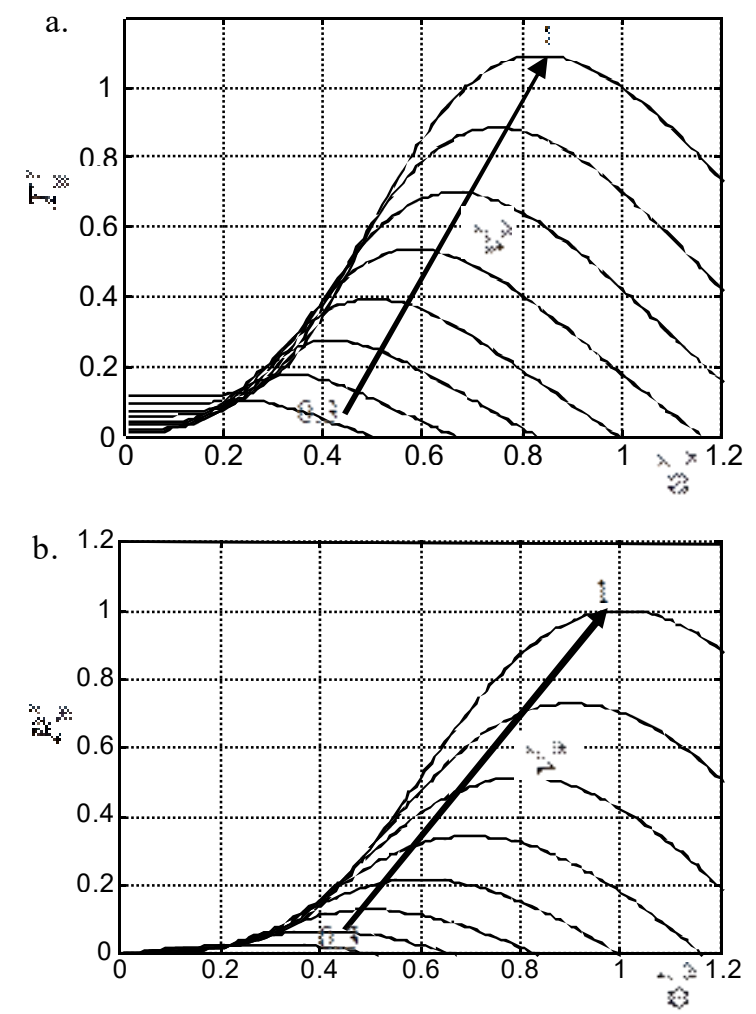

Figure 2. Wind turbine characteristics: a.) torque b.) power, versus relative angular velocity curves at different wind speeds. 


\section{Water turbine model}

The water turbine features depend significantly on its construction. It performance is visualised usually on the water flow - turbine velocity plane (known as a hill chart) which presents isolines connecting the points that have the same efficiency. The example hill chart of the propeller turbine which is often used in SHPs is presented in Fig. 3a. Basing on this relation the torque function may be determined by (4) and approximated by the function (5) (Fig. 3b) [13].

$$
\begin{gathered}
T_{h}=\frac{9.81 \cdot \rho_{h} \cdot Q \cdot H \cdot \eta}{\omega_{h}} \\
T_{h}=C_{H} \cdot\left(a(\alpha) \cdot \omega_{h}^{2}+b(\alpha) \cdot \omega_{h}+c(\alpha)\right)
\end{gathered}
$$

where: $\rho_{h}$ - water density $\left(\mathrm{kg} / \mathrm{m}^{3}\right)$,

$Q$ - water flow (turbine discharge) $\left(\mathrm{m}^{3} / \mathrm{s}\right)$,

$H$ - difference of water level between the upstream level and the downstream level (water head) (m),

$\eta$ - turbine efficiency (-),

$\omega_{h}$ - water turbine angular velocity $(\mathrm{rad} / \mathrm{s})$,

$C_{H}$ - water level coefficient (-),

$a(\alpha), b(\alpha), c(\alpha)$ - function coefficients (-),

$\alpha$ - guide vane angle (-).

Taking the nominal parameters: $Q_{N}, H_{N}, \eta_{N}, \alpha_{N}$, $\omega_{h N}$ as reference values the function coefficients may be approximated by a polynomial function of the guide vane angle (6).

$$
\begin{aligned}
& a(\alpha)=-0.44423 \alpha^{3}+2.32343 \alpha^{2}-3.12 \alpha \\
& b(\alpha)=3.6548 \alpha^{5}-13.58 \alpha^{4}+15.256 \alpha^{3}-5.552 \alpha^{2}+2.094 \alpha \\
& c(\alpha)=-2.4484 \alpha^{5}+10.09 \alpha^{4}-13.493 \alpha^{3}+5.872 \alpha^{2}+0.347 \alpha
\end{aligned}
$$

The analysis presented in this paper concerns only the reservoir SHP under the changeable water head. To simplify the analysis the guide vane angle will be set to $100 \%$. The water head influences the turbine torque through the water level coefficient and the turbine velocity which relative formula is given in (7).

$$
\begin{gathered}
T_{h}^{r}=C_{H}^{r} \cdot\left(a(\alpha) \cdot \omega_{h}^{r 2}+b(\alpha) \cdot \omega_{h}^{r}+c(\alpha)\right) \\
C_{H}^{r}=\left(\frac{H}{H_{N}}\right)^{\frac{3}{2}}, \omega_{h}^{r}=\frac{\omega_{h}}{\omega_{h N}} \sqrt{\frac{H}{H_{N}}}
\end{gathered}
$$

The curves of turbine torque in the relative values are shown in Fig. 4a
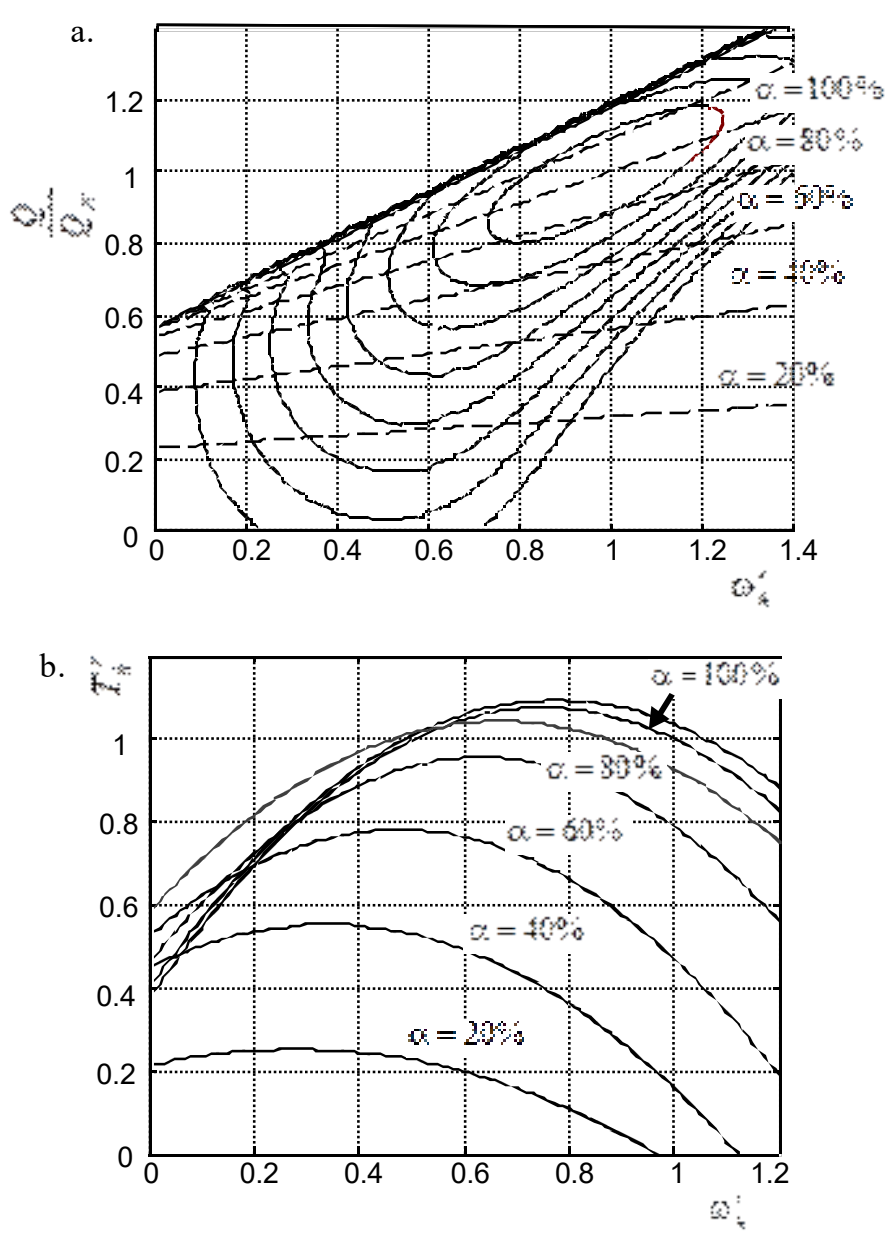

Figure 3. Propeller turbine characteristics: a.) hill chart (solid efficiency isolines, dashed - guide vane angles), b.) turbine torque curves at different guide vane angles and nominal head.

\section{Tests}

\subsection{Inverter description and MPPT dynamic test}

The investigated single-phase microinverter is the commercially available Soladin 600 with parameters listed in table 1 . The analysis of the topology showed that it is a dual-stage topology without inherent

Table 1. Chosen inverter parameters given by the Mastervolt

\begin{tabular}{|l|l|l|l|}
\hline $\begin{array}{l}\text { Parameter of } \\
\text { input (solar) }\end{array}$ & Value & $\begin{array}{l}\text { Parameter of } \\
\text { output (grid) }\end{array}$ & Value \\
\hline $\begin{array}{l}\text { Nominal power } \\
\text { at } 25^{\circ} \mathrm{C}\end{array}$ & $535 \mathrm{~W}$ & Net voltage & $230 \mathrm{~V}$ \\
\hline MPP voltage & $40-125 \mathrm{VDC}$ & $\begin{array}{l}\text { Maximum } \\
\text { current }\end{array}$ & $2.25 \mathrm{~A}$ \\
\hline MPP tracker & $>99 \% \mathrm{MPP}$ & Power factor & 0.99 \\
\hline $\begin{array}{l}\text { Nom. rated } \\
\text { current }\end{array}$ & $8 \mathrm{~A}$ & $\begin{array}{l}\text { European } \\
\text { efficiency }\end{array}$ & $91 \%$ \\
\hline
\end{tabular}



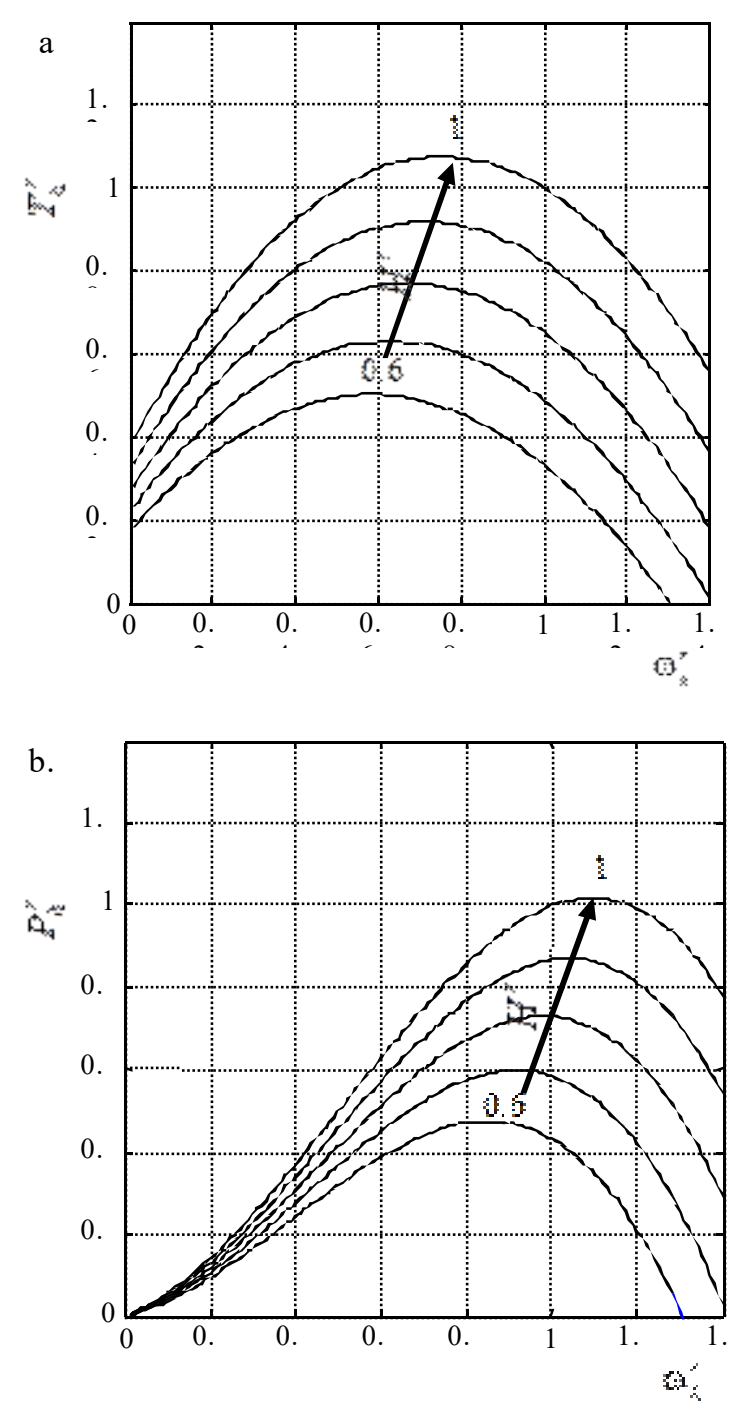

Figure 4. Water turbine characteristics: a.) relative torque b.) relative power, versus relative turbine angular velocity at different water heads.

power decoupling, which is similar to the Soladin 120 described already in the literature [3,15] (Fig. 5). The capacitor connected in parallel to the PV system work as an energy buffer.

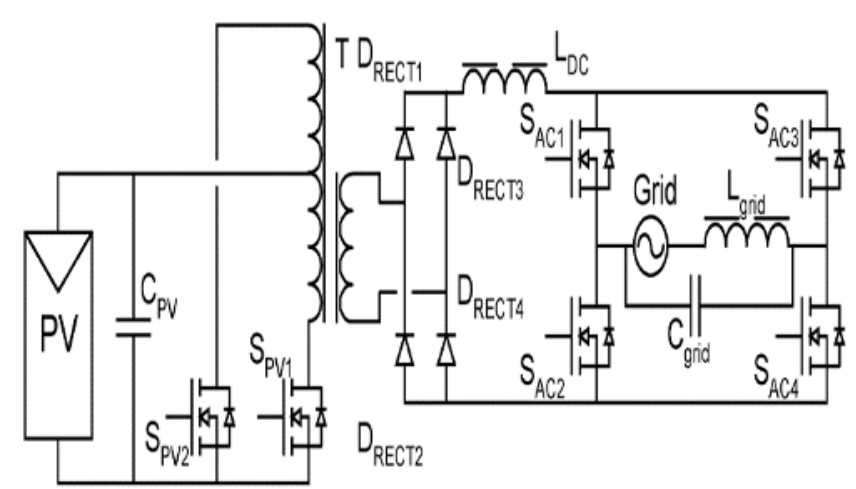

Figure 5. Topology of the microinverter Soladin $120[3,14]$.

The dynamic tests of the inverter coupled with the PV panels (two Q-cells 250W connected in series) showed its fast MPPT response to the step change of the irradiance (Fig. 6). The time constant may be estimated at about 1second.
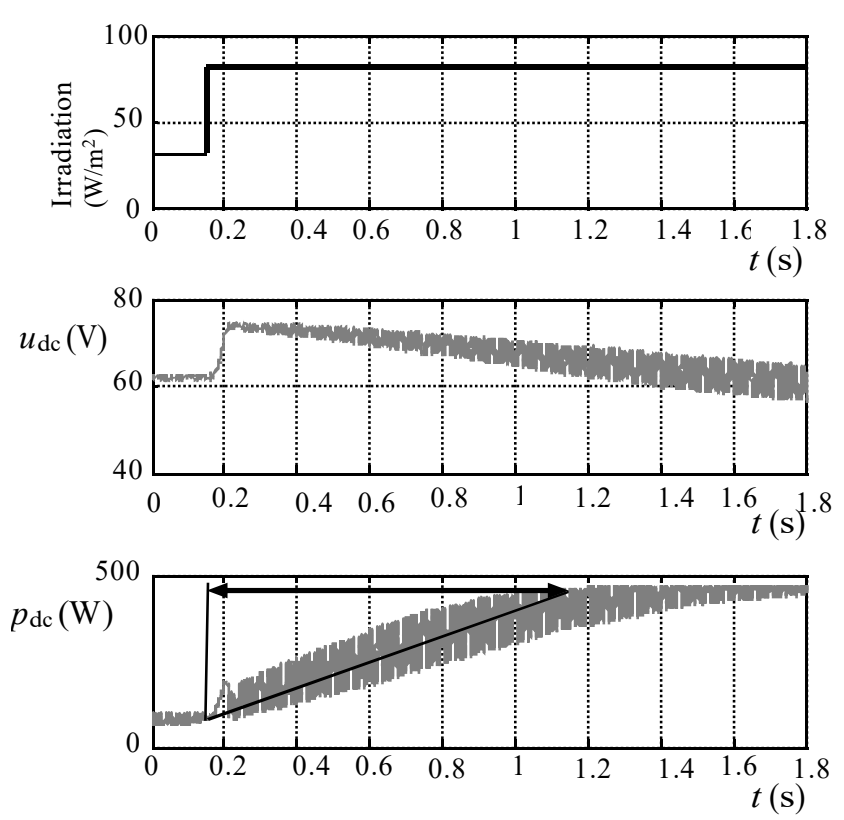

Figure 6. Dynamic test of inverter MPPT: a.) solar irradiation, b.) voltage across the PV modules, c.) generated DC power, for step-change of the irradiation.

\subsection{Test bench description}

The modelled torque of the wind turbine and the water turbine are realised by an induction motor (IM) fed by the inverter with the vector control. The PLC controller calculates the actual torque from relation (3) or (7) as a function of the angular generator velocity using reference values listed in Table 2 . The control signals (velocity and torque) are transmitted using analogue voltage signals what increase the system dynamic. The longest time constant (about 1s) is introduced by the inverter controller and the induction motor inertia. The motor is coupled by the elastic clutch with the permanent magnet synchronous generator (PMSG). The nominal parameters of the machines are shown in Table 2. In order to combine the PMSG with the microinverter the diode rectifier bridge is used (Fig. 7).

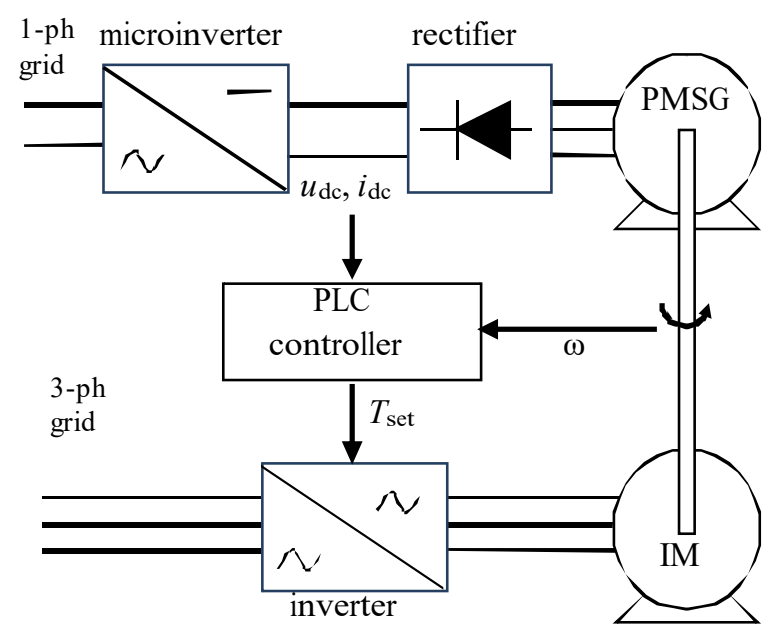

Figure 7. Energy conversion system structure of the laboratory test bench. 
In this topology the DC current is proportional to the PMSG torque while the DC voltage is a linear relation of the generator velocity in a steady state operation [16].

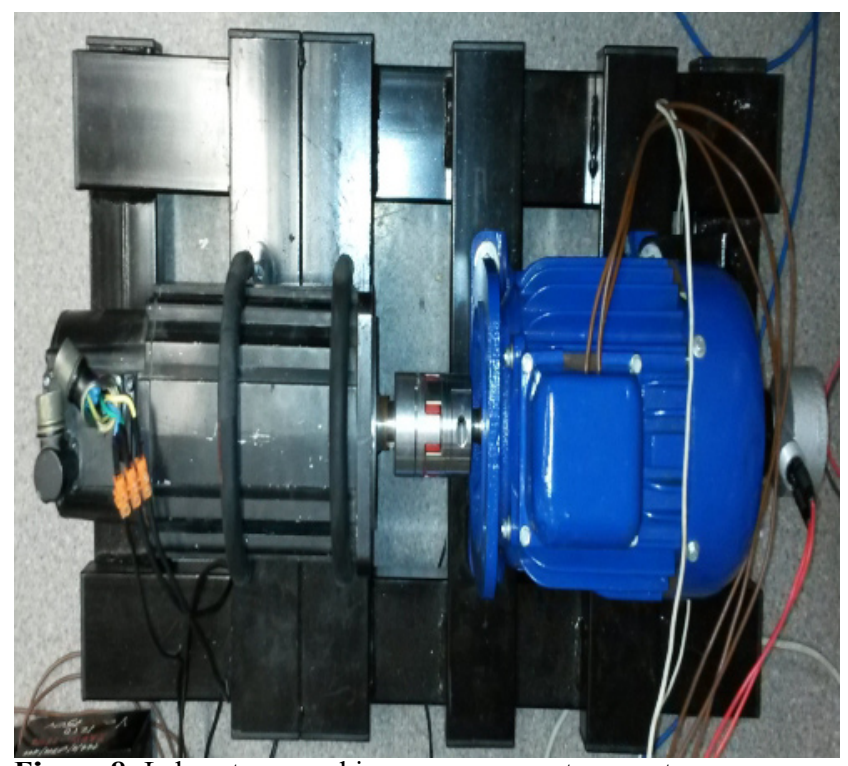

Figure 8. Laboratory machines - permanent magnet

synchronous generator coupled with induction motor of $0.8 \mathrm{~kW}$.

The diode bridge introduces additional frequencies into the dc current (Fig. 9). Besides the $100 \mathrm{~Hz}$ component generated by the microinverter MPPT control [17] which is visible in Fig. 9a, the current spectrum contains components at sixth multiples of the motor voltage frequency (Fig. 9b). This may affect the MPP tracking accuracy The current disturbances caused by the diode rectifier do not affect the key parameters of the microinverter. The conversion efficiency is above the $91 \%$ in the whole range of measured power (Fig. 10). power conditions become significant thus the power factor exceeds value 0.95 above the $40 \%$ of the nominal power.

Table 2. Nominal machine parameters and reference values

\begin{tabular}{|c|l|c|l|l|l|}
\hline \multicolumn{2}{|l|}{ PMSG parameters } & \multicolumn{2}{l|}{ IM parameters } & \multicolumn{2}{l|}{$\begin{array}{l}\text { Reference } \\
\text { values }\end{array}$} \\
\hline $\mathrm{P}_{\mathrm{N}}$ & $3.5 \mathrm{k} \mathrm{W}$ & $\mathrm{P}_{\mathrm{N}}$ & $0.8 \mathrm{~kW}$ & $\omega$ & $\begin{array}{l}104,7 \\
\mathrm{rpm}\end{array}$ \\
\hline $\mathrm{IN}_{\mathrm{N}}$ & $11 \mathrm{~A}$ & $\mathrm{I}_{\mathrm{N}}$ & $2.5 \mathrm{~A}$ & $\mathrm{P}$ & $500 \mathrm{~W}$ \\
\hline eff & $111 \mathrm{~V} / 1000 \mathrm{rpm}$ & $\mathrm{n}_{\mathrm{N}}$ & $1420 \mathrm{rpm}$ & $\mathrm{I}_{\mathrm{dc}}$ & $6 \mathrm{~A}$ \\
\hline $\mathrm{T}_{\mathrm{N}}$ & $12 \mathrm{Nm}$ & $\mathrm{U}_{\mathrm{N}}$ & $400 \mathrm{~V}$ & & \\
\hline
\end{tabular}

a.

$u_{\mathrm{dc}}$

(V)

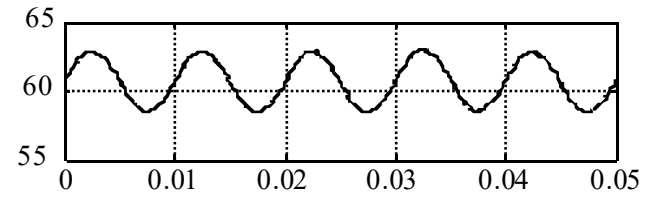

$i_{\mathrm{dc}}$
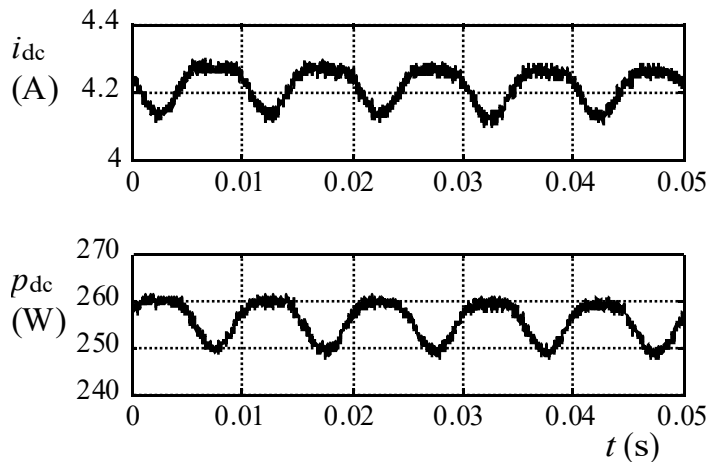

b.

(V)
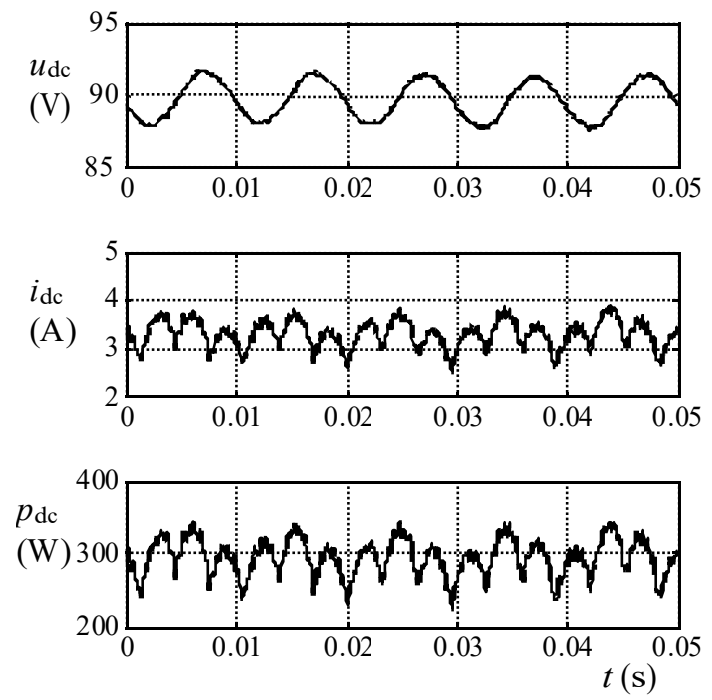

Figure 9. Time domain waveforms of DC signals of microinverter supplied by: a.) PV system b.) PMSG with diode rectifier.

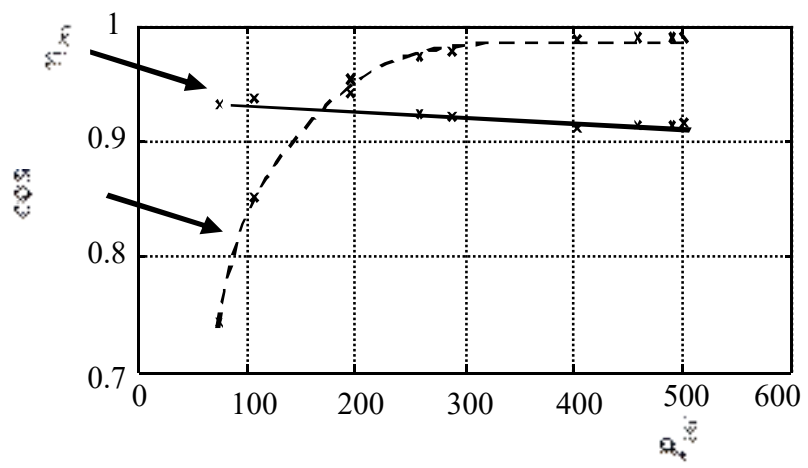

Figure 10. Performace of microinverter supplied by PMSG through diode bridge rectifier: a.) efficiency (solid line), b.) power factor (dashed line) 
a.

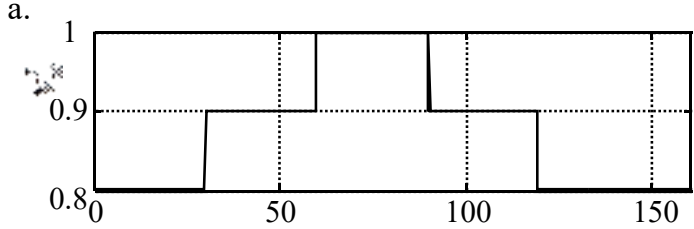

b.
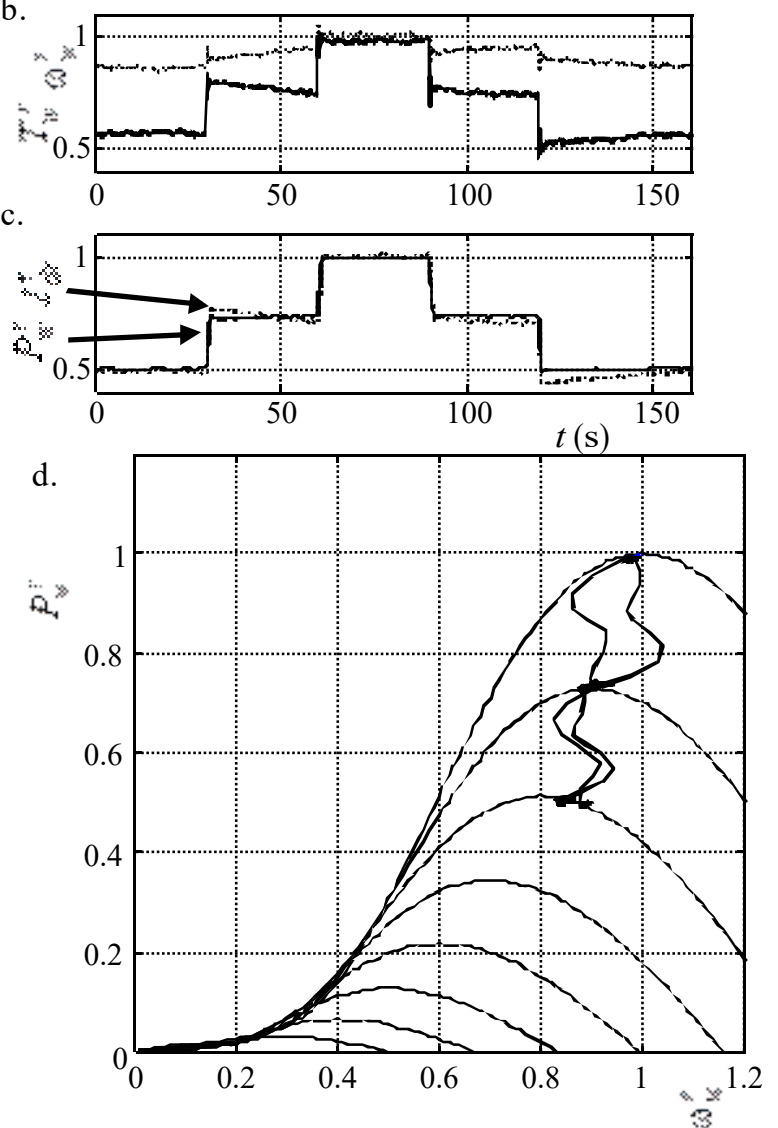

Figure 11. Dynamic response of wind turbine system: b.) angular velocity and turbine torque, c.) dc current and output power, d.) output power-angular velocity plane, to the step changes of wind speed a.).

\subsection{Tests of wind turbine system}

The operation effectiveness of the PV microinverter in the wind turbine system is assessed basing on the two tests. The dynamic performance is checked by stepping up and down the wind speed (Fig. 11).

The two stages of the MPPT algorithm are visible in every step change. Firstly, the step change of the wind $v_{w}^{r}$ causes the fast turbine torque $T_{w}^{r}$ modification what results in the speed $\omega_{w}^{r}$ variation. The tracking algorithm reacts immediately by the dc current $I_{d c}^{r}$ modification to the voltage gradient of the synchronous generator which is proportional to the turbine speed. The tracking speed is satisfactory under the wind speed fast changes. The second stage is the seeking process of the MPP basing on the P\&O method. The power curves near the MPP are plane for the constant wind speed thus the control process results in the small power changes in these areas (Fig. 11c).
The system efficiency is validated under a realistic wind profile (Fig. 12a). The power coefficient $C_{p}^{r}$ (Fig. 12b) is affected by the wind speed changes especially at low wind speed values where the power curves are flatten.

a.

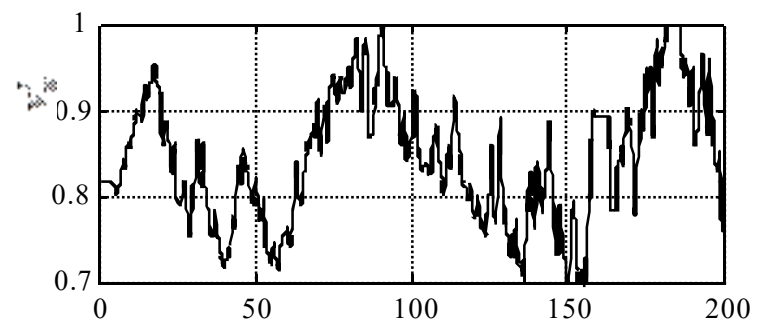

b.
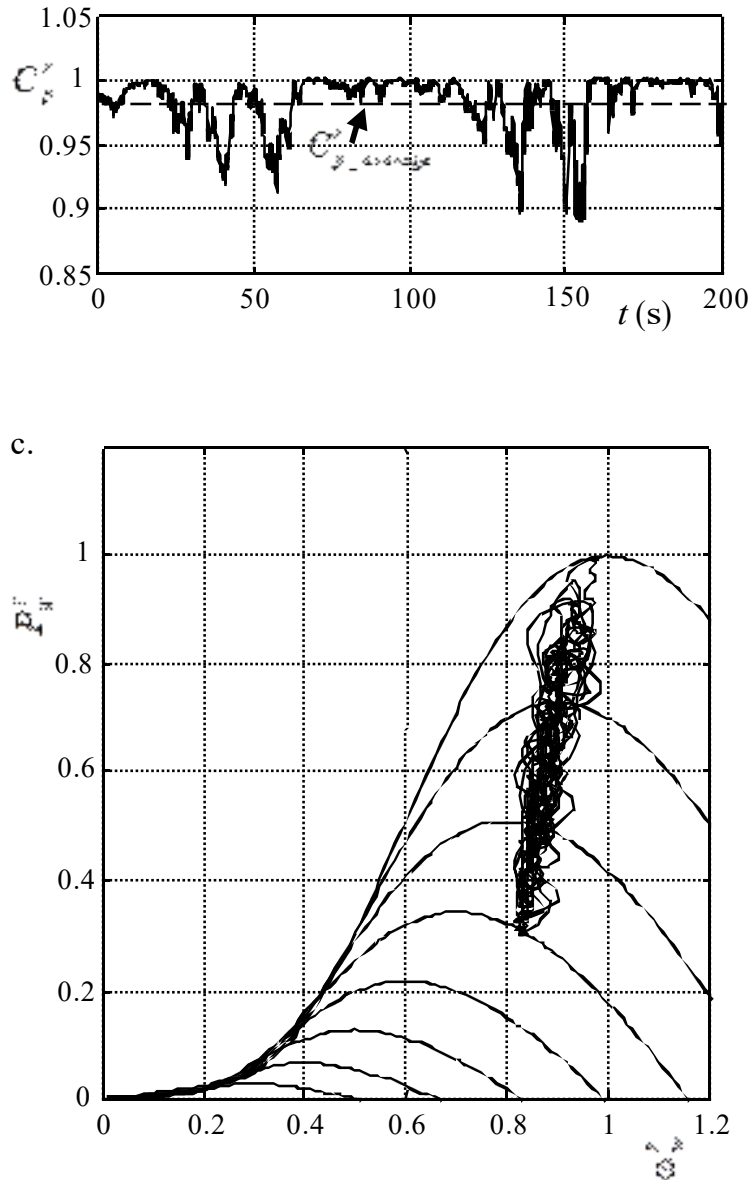

Figure 12. System performance under realistic wind profile: a.) wind speed, b.) power coefficient, c.) power versus angular velocity, in relative values.

The average power coefficient in a relative scale corresponding to the MPP tracking accuracy (8) [18] equals 0.983 . The value of the average power coefficient equals 0.472 in a natural unit.

$$
\eta_{M P P T}=\frac{P^{r}}{P_{M P P}^{r}}=C_{p}^{r}
$$

where:

$P^{r}$ - relative output power

$P_{M P P}^{r}$ - relative power for maximum power point 


\subsection{Tests of water turbine system}

The performance analysis of the PV microinverter in the water turbine system is evaluated similarly to the previous case. Here the water head $H^{r}$ is the variable parameter. Its step changes cause the two stages reaction of the MPPT algorithm. The dynamic response to the stepping up and down of the input variable is presented in Fig. 13.

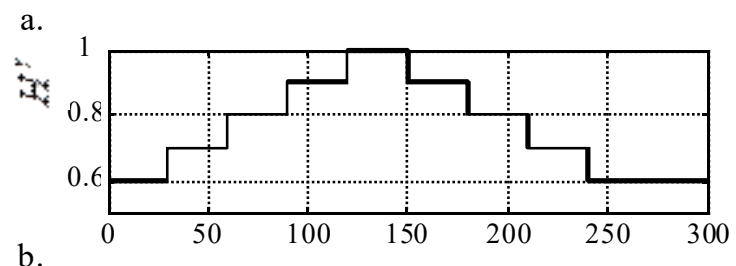

b.

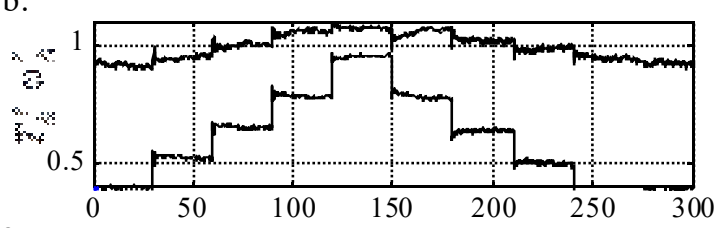

c.

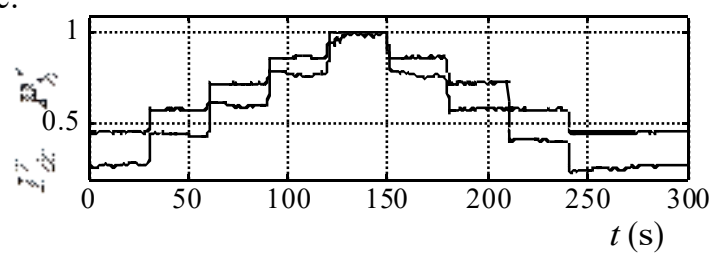

d.

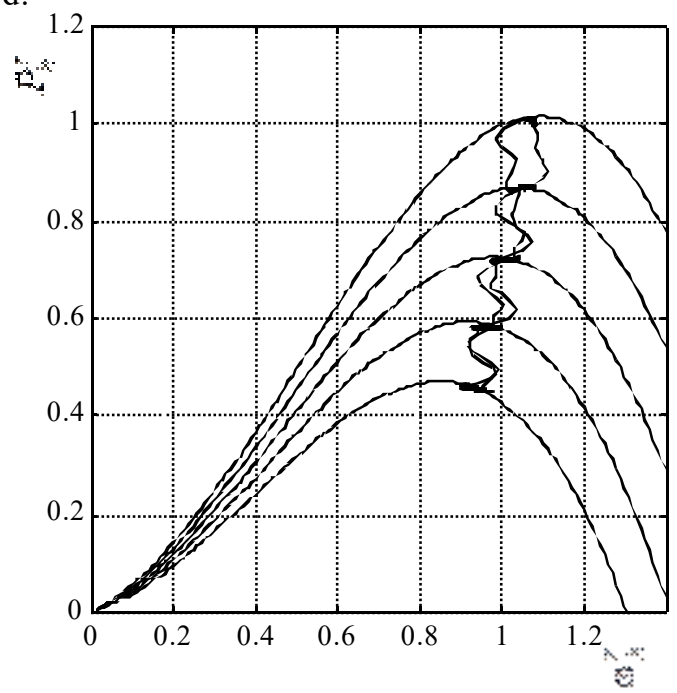

Figure 13. Dynamic response of water turbine system:

b.) angular velocity and turbine torque, c.) dc current and output power, d.) output power-angular velocity plane, to the step changes of water head a.).

The propeller water turbine is characterized by the relatively small influence of the water head variation into the output power defined by (7). That is way the same step changes of the variable parameter (each by $10 \%$ of the relative value) results in the smaller power modifications than in the wind system. This decreases the MPPT seeking time.

The realistic water profile used for the system test (Fig. 14a) presents the water head changes in the reservoir SHP. The gradient of the water head depends on the tank capacity, turbine discharge and tank supply volume. Some fluctuations result from the water surface waving and the sensor accuracy. Slow changes and low amplitude of the variations improves the operation curve on the output power - angular velocity plane (Fig. 14c). The average MPP tracking accuracy defined by (8) equals 0.957 (Fig. $14 \mathrm{~b})$. This result is worse than for the wind system about $2.5 \%$. The difference of the MPPT effectiveness is caused by the profile of input function and the power function shape.

a.

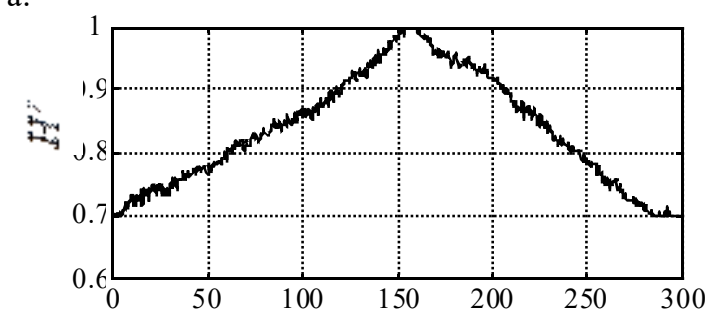

b.
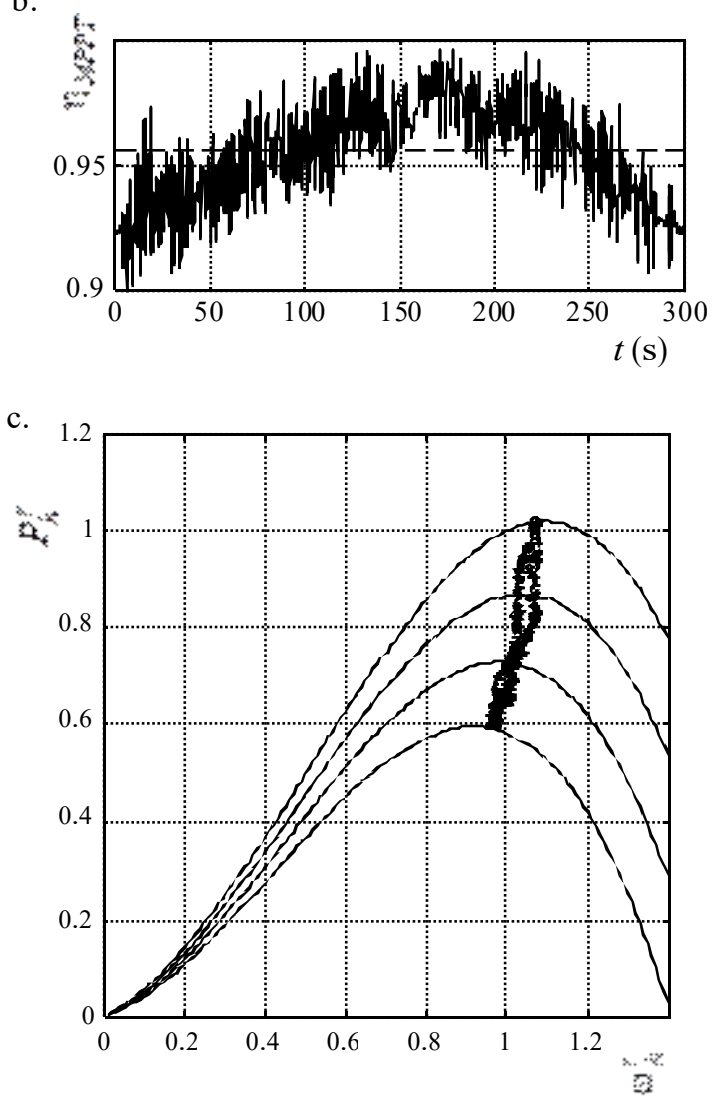

Figure 14. System performance under realistic water head profile: a.) water head, b.) tracking accuracy, c.) power versus angular velocity, in relative values.

\section{Summary}

This article presents the possibility of using the commercially available PV microinverter in the water and wind applications. The described models of the low power wind turbine and the reservoir small water turbine are based on the torque characteristics in a steady state. The parameters are scaled into relative variables in order to make the performance comparison. The dynamic features are introduced by the laboratory inverter 
and the machines. The conducted dynamic tests, in the form of stepping up and down the input function, have showed fast systems response comparable in the both cases. The energy production effectiveness of the chosen energy sources with the using of the PV microinverter cannot be easily compared. While this parameter corresponds directly to the power factor for the wind system, the water system requires taking into account the nonlinear efficiency characteristic (hill chart) of the water turbine (Fig. 3a). Therefore the MPPT efficiency parameter was used to compare the system effectiveness. The MPPT tracking accuracy tested under the realistic profiles is similar for both cases: $98 \%$ and $96 \%$ respectively for the wind and the water systems. These results prove the satisfactory performance of the MPPT method and the PV microinverter in the presented applications.

In conclusion, it may be claimed that the chosen small renewable sources may be controlled by the common indirect MPPT method implemented in the universal microinverter with the satisfactory effectiveness. The designing process of the inverter and the control method for the specific small systems is debatable.

\section{References}

1. S. Narendiran, ICCPCT Conf. P., 564-567, (2013)

2. H. Haibing, S. Harb, N. Kutkut, I. Batarseh, Z.J. Shen, IEEE Trans. Power Electron., 28, 6, 2711-2726, (2013)

3. S.B. Kjaer, J.K. Pedersen, F. Blaabjerg, Trans. Ind. Appl. IEEE, 41, 5, 1292-1306, (2005)

4. J.D. Bastidas-Rodriguez, E. Franco, G. Petrone, A. Ramos-Paja, G. Spagnuolo, IET Power Electron., 7, 6, 1396-1413, (2014)

5. B. Subudhi, R. Pradhan, IEEE Trans. Sustainable Energy, 4, 1, 89-98, (2013)

6. S.M. Raza Kazmi, H. Goto, G. Hai-Jiao, O. Ichinokura, IEEE ECCE Conf. P., 4075-4082, (2010)

7. X. Yuanye, K.H. Ahmed, B.W. Williams, IEEE Trans. Ind. Electron., 60, 3, 1122-1132, (2013)

8. J. Fraile-Ardanuy, J.R. Wilhelmi, J.J. Fraile-Mora, J.I. Perez, IEEE Trans. Energy Convers., 21,2, (2006)

9. D. Borkowski, T. Węgiel, IEEE Trans. Energy Convers., 28, 2, 452-459, (2013)

10. W. Mazgaj, Z. Szular, T. Węgiel, T. Sobczyk, Electrical Rewiev, 87, 5, 282-287, (2011)

11. L. Belhadji, S. Bacha, I. Munteanu, A. Rumeau, D. Roye, IEEE Trans. Energy Convers., 28, 1, 34-43, (2013)

12. Borghetti, M. DiSilvestro, G. Naldi, M. Paolone, M. Alberli, PSCC Conf. P., 447-454, (2008)

13. D. Borkowski, Technical Transactions - Electrical Engineering, 1-E, 15-24, (2015)

14. S. Heier, Grid Integration of Wind Energy Conversion Systems, Hoboken, NJ: Wiley, (2006)

15. S. B. Kjaer, Design and control of an inverter for photovoltaic applications, $\mathrm{Ph}$.D. dissertation, Inst. Energy Technol., Aalborg University, Denmark, (2005)
16. Z.M. Dalala, Z.U. Zahid, Y. Wensong, C. Younghoon, L. Jih-Sheng, IEEE Trans. Energy Convers, 28, 3, 756-767, (2013)

17. T. Kerekes, R. Teodorescu, M. Liserre, R. Mastromauro, A. Dell'Aquila, , IEEE $11^{\text {th }}$ OPTIM Conf. P., 427-432, (2008)

18. T. Andrejašič, M. Jankovec, M. Topič, IET Renew. Power Gen., 5, 4, 281-286, (2011) 